Listen to a prig who says he has worked himself into a naturalist by means of the plan advocated in most of the late books on botany and zoölogy. "How did you become so great a naturalist?""Why, you see, when I was about twelve years old, I received a free ticket to a lecture on natural history by Professor — , and, as it was free, I of course went, and there I heard how a beginner should start. At this time I did not know the name of any animal. I properly despised those who did. I did not know a cat from a dog. When bitten, I simply cried, and ran home. I did not ask, I did not care whether it was a mosquito, a bumblebee, or a rattlesnake that bit me, or by which end I was bitten. I went home from the lecture, and purchased a compound microscope, a dissecting microscope, a set of dissecting instruments, a set of injecting instruments, a microtome, and forty bottles of hardening, staining, and mounting fluids. On account of the discounts, I was able to purchase them for two hundred dollars. Then I went and gathered some Protomonas, amoebae, and other protozoans, and from these I worked out the whole problem of life. I was very careful to take but little notice of the external organs, since great harm always arises from looking at outside parts. The proper way is always to begin with the insides. After this good and proper beginning, I soon became a great naturalist." This is all nonsense. No naturalist ever began in this way. As well try to make a child learn all about the letters and syllables which form a word - its root, derivation, and history, and all its prefixes and suffixes - before allowing him to use it, as to try the same plan in zoölogy. Prof. L. Agassiz said that all the great naturalists he ever knew, both in Europe and America, began their work by making and naming collections. The critic will say again 'that science had changed within the last eventful quarter-century.' Some things cannot be reversed, and this is one of them. Those who have recently had so much to say about teaching beginners are the ones who never have beginners to teach: they are university professors, with plenty of time at their command, scores of microscopes to work with, and, as students, only those who elect to take the subject because they have passed through all the necessary preliminary stages.

A TEACHer.

\section{For what purpose mosquitoes were created.}

Your mention of Dr. Finlay's view that yellowfever may be propagated by mosquito-bites reminds me of the following: In 1839, during a yellow-fever epidemic in Augusta, Ga., no case originated at Summerville, a neighboring suburb among the sand hills. There were then no mosquitoes at Summerville, which was approached by a rather circuitous route from Augusta. Some years after, a straight, broad road was built through swamps directly to the sand hills ; cisterns were also built, and mosquitoes appeared and became an intolerable pest. During the yellow-fever epidemic of 1854 a number of cases originated at the sand hills, now abounding with mosquitoes. Mosquitoes often invade sections where they were previously unknown and make permanent settlement. Mr. Mimms of Aiken, S.C., told me that the first mosquito seen in that town came from the cars on the South Carolina railroad. They are abundant there now. Dr. I. P. Garrin satisfied the medical faculty and authorities of Augusta that the yellow-fever in 1839 reached the town in freight cars on this railroad. Dr. Roe, late of Alabama, informed me that once when quarantined for yellowfever near Staten Island he collected a dozen or more varieties of mosquitoes from the holds of as many vessels there in quarantine from yellow-fever ports. They had evidently taken passage from the infected ports. I do not remember a locality subject to malarial fever that is not infested with mosquitoes.

Beech Island. S.C., Nov. 3.

HARRY HAMMOND.

\section{A long skull.}

I was much struck with the very long and narrow proportions of a skull in the collection of W. W. Adams of Mapleton, N. Y., and which was exhumed with others in Cayuga county. I had not time to make a thorough examination of it, but Mr. Adams has kindly sent me a photograph, and also an outline.

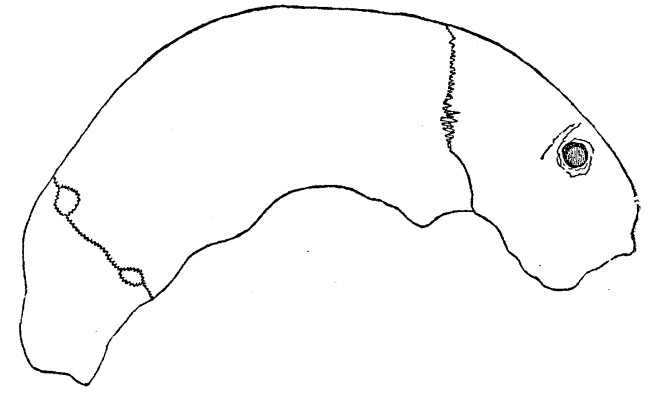

The photograph shows what to him was the most interesting feature, a circular hole, of a little over a quarter of an inch in diameter, in the anterior section, which he supposed to be made by a bullet, and which was doubtless the cause of death, from its general character. The proportions interested me more, and these the photograph does not clearly show. Impressed by the elongated character of the cranium, I sent to Mr. Adams for accurate measurements, and he gives the length as eight inches, and the width four and a half. The narrowest skull mentioned in Dr. Morton's 'Crania Americana' is that of a Cayuga chief, in which the longitudinal diameter was 7.8 , and the parietal 5.1 ; the cephalic index being 65.4. In this Cayuga skull the cephalic index would be 5.625, if the measurements are exact, as I suppose they are.

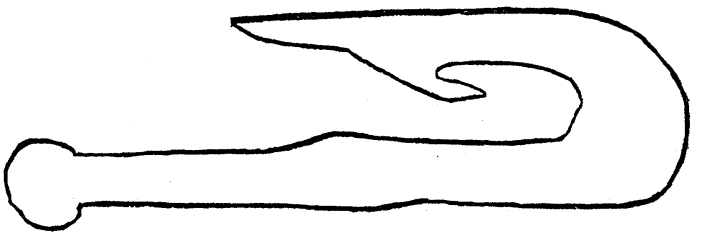

I announced some time ago my discovery of the barb of a horn fish-hook, which supplemented the figure I furnished for Dr. Rau's 'Prehistoric fishing.' It gives me pleasure to say that Mr. J. L. Twining of Copenhagen, N. Y., has another of these rare articles, found near Watertown. It closely resembles Mr. Ledyard's specimen, but is more compressed.

Baldwinsville, N.Y. 